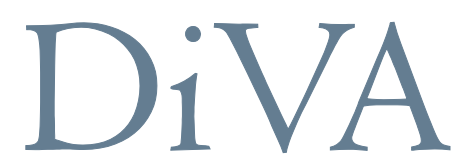

http://uu.diva-portal.org

This is an author produced version of a paper published in Journal of Psychosomatic Obstetrics \& Gynecology. This paper has been peerreviewed but does not include the final publisher proof-corrections or journal pagination.

Citation for the published paper:

Liljas Stålhandske M., Ekstrand M., Tydén T.

"Women's existential experiences within Swedish abortion care"

Journal of Psychosomatic Obstetrics \& Gynecology, 2011, Vol. 32, No. 1, pp. 35-41

URL: http://dx.doi.org/10.3109/0167482X.2010.545457

Access to the published version may require subscription. 


\section{Women's existential experiences within Swedish abortion care}

\section{Title page}

Title: Women's existential experiences within Swedish abortion care

1. Maria Liljas Stålhandske, $\mathbf{P h D}$, Researcher (corresponding author) Uppsala Religion and Society Research Centre

Uppsala University, Box 511

SE 75120 UPPSALA, Sweden

Phone: +46704568006

Mail: maria.liljas@crs.uu.se

2. Maria Ekstrand, $\mathrm{PhD}$, Researcher

Department of Public Health and Caring Sciences, Uppsala University

3. Tanja Tydén, Professor

Department of Public Health and Caring Sciences, Uppsala University

Running title: Abortion experiences

Key words: abortion, abortion care, psychological wellbeing, women's health, existential support, existential experience, Sweden 


\section{Abstract}

Objective: To explore Swedish women's experiences of clinical abortion care in relation to their need for existential support.

Methods: Individual in-depth interviews with 24 women with previous experience of unwanted pregnancy and abortion. Participants were recruited between 2006 and 2009. Interviews were analysed by latent content analysis.

Findings: Although the women had similar experiences of the abortion care offered, the needs they expressed differed. Swedish abortion care was described as rational and neutral, with physical issues dominating over existential ones. For some women, the medical procedures triggered existential experiences of life, meaning, and morality. While some women abstained from any form of existential support, others expressed a need to reflect upon the existential aspects and/or to reconcile their decision emotionally.

Conclusion: As women's needs for existential support in relation to abortion vary, women can be disappointed with the personnel's ability to respond to their thoughts and feelings related to the abortion. To ensure abortion care personnel meet the physical, psychological, and existential needs of each patient, better resources and new lines of education are needed to ensure abortion personnel are equipped to deal with the existential aspects of abortion care. 


\section{Introduction}

In Sweden, public opinion on abortion is liberal. The present Swedish abortion law was passed in 1975 and permits pregnancy termination until the $18^{\text {th }}$ week of gestation, solely on request of the pregnant woman. While abortion remains controversial in many countries, even among those involved in the abortion care ${ }^{1,2}$, attitudes among Swedish gynaecologists and midwives regarding legal abortion are overwhelmingly positive ${ }^{3,4}$.

Deciding on abortion in Sweden is more a question of life expectancies than of issues related to personal health ${ }^{5}$. Although psychological distress after abortion is rare ${ }^{6-10}$, the abortion decision and the abortion itself may comprise a combination of strong and contradictory emotions related to existential issues, such as life and death, morality and meaning ${ }^{11-14}$. Since unwanted pregnancy concerns the potential of human life and demands an irreversible decision it includes existential aspects that can be difficult to deal with. Debriefing methods are well established in crisis intervention and counselling, which enables groups and individuals to express and deal with complicated experiences ${ }^{15,16}$. When a Swedish woman decides to abort, she is referred to a clinical environment where medical issues, rather than emotional or existential ones, are in focus.

In two qualitative studies ${ }^{17,18}$, female abortion patients refer to abortion care as predominantly based on physical aspects, and describe the personnel involved as not considering the women's individual and emotional needs. Research in this area is limited, and studies focusing on the existential aspects of abortion care are lacking. The experience of unwanted pregnancy often includes strong emotions, sometimes related to existential issues. Yet, when a woman decides to abort, she is referred to a medical environment, predominantly focusing on physical aspects. 
The aim of this study was to explore Swedish women's experiences of clinical abortion care, in relation to their need for existential support. The latter refers to support focusing on the women's cognitive and emotional responses to the existential aspects of the unwanted pregnancy. 


\section{Methods}

\section{Study outline}

The study was explorative and qualitative in design and used individual, semi-structured indepth interviews and a questionnaire (designed and pilot tested for the study by the first author) with Swedish-speaking women with previous experience of unwanted pregnancy and abortion. The women were recruited between 2006 and 2009, at a student health clinic in Uppsala, Sweden and through an advert in a student magazine. Inclusion criteria were wide, and any woman with previous experience of abortion within Swedish health care was welcome to take part. The three authors led the face-to-face interviews, which lasted between 60-120 minutes. All authors are researchers within sexual and reproductive health, two of whom are also midwifes experienced in clinical abortion care.

Each interview session started with time for the women to fill out the questionnaire, which contained socio-demographic questions and questions about thoughts, feelings and practices in relation to the abortion. When the questionnaire was completed, the interviewer encouraged the woman to tell her story. The interviewer used both an interview guide and the completed questionnaire to make sure all topics of interest were discussed. The interviewer encouraged each participant to explore her experiences thoroughly by using detailed oriented probes and elaboration probes, in order to elicit deeper reflection ${ }^{19}$.

\section{Participants}

The sample consisted of women $(\mathrm{n}=24)$ aged 21 to 57, with previous abortion experience: sociodemographic background data are presented in Table 1.

\section{Data analysis}

The interviews were tape-recorded, transcribed verbatim, and analysed by latent content analysis in three steps:

1. The first author read the transcribed text and performed 
a. a meaning concentration by constructing condensed stories for each interview

b. a meaning categorisation by identifying and coding meaning units from the complete transcripts and creating preliminary categories

2. All authors read the transcripts, and the condensed stories, codes and categories created by the first author. The content and boundaries of each category were continually discussed and refined.

3. All coded meaning units, with information relevant to the aim of the study, were referred to mutually exclusive categories ${ }^{20,21}$.

The questionnaires were used to obtain socio-demographic data and to validate parts of the content analysis. The study was approved by the Regional Ethical Committee in Uppsala $(2008 / 289)$. 


\section{Findings}

The content analysis resulted in three categories and six subcategories (Table 2).

\section{Medical procedures evoked existential experiences}

The women described how specific medical procedures made them realise, from an existential perspective, what they were going through.

The ultrasound made the pregnancy real. Some of the women had avoided thinking about the pregnancy in human terms. During the ultrasound examination, it often became more difficult for them to maintain a neutral view, which made the situation distressing:

It was the only time when it felt a bit uncomfortable. /---/ it was probably about then that I realised that it actually was the beginning of a life. That it was a foetus or whatever you should call it. (IP12, medical abortion at age 23)

Some women associated ultrasound examinations with the happy expectations of a planned pregnancy: to go through the examination without positive anticipation felt difficult:

I thought that this is a really happy moment for so many to see because the doctor said that this looks good, everything is normal and so on, and then it felt quite difficult to not be able to be happy. /---/ it felt a bit weird to look at it like a problem and get rid of it instead of seeing it as the gift that it really should be. (IP6, surgical reabortion at age 19)

Taking the pill made the choice irrevocable. Women who had medical abortions described how taking the first pill felt like an ultimate step. When the nurse had clarified the pill would end the pregnancy, the women became aware the decision was in their hands and the abortion could not be reversed:

It was probably the heaviest moment during the abortion when you took that abortion pill. When she said so clearly that 'now it is irrevocable, I am not trying to make you decide about anything here, but, just so you know, from this moment, it is irrevocable.' And then I apologised to the foetus. (IP14, medical abortion at age 26)

\section{Personnel avoided the existential aspects of the situation}

The women presented a unanimous picture of Swedish abortion care being neutral, rational, and efficient. However, there were differences in the way it was experienced; some appreciated its neutrality and rationality, others found it insufficient for their needs. 


\section{Women's existential experiences... \\ Journal of Psychosomatic Obstetrics and Gynecology}

The personnel never questioned the decision. Some women specifically mentioned the neutral

attitude of the personnel as something positive, as they had expected a more judgmental attitude:

I became very grateful for the Swedish care system... you call the day after the pregnancy test and no one is questioning you, and you pay 80 quid, or whatever it is, and you get everything. It's fantastic really. (IP13, medical abortion at age 23)

Other women felt abortion was the expected choice, and described how neither friends nor medical personnel considered childbirth as a possible option in their circumstances. This made it difficult for them to talk about their mixed feelings. One woman, who was against abortion in principal, described how the counsellor convinced her to have the abortion:

I told her that I was against abortion and I explained my situation, that I am a student and that I didn't have a stable relationship and she simply said 'well, but you do have to think about your future'. And then she said 'would you like to see a doctor next week?' It was really her initiative. It was she who suggested it. (IP7, surgical abortion at age 22)

For another woman, it was difficult to question the abortion decision, as she felt everyone around her thought terminating the pregnancy was the only thing to do: this held her back from voicing her hesitation at every opportunity. Instead, she wished the personnel had questioned her decision:

Because, I guess I thought it was difficult to question a decision that everyone else thought was right, in some way. /---/ the healthcare staff are apparently not allowed to question my decision. But I wish they had done so. (IP18, medical abortion at age 22)

The personnel focused on physical rather than emotional issues. Most women described the abortion care as rational, pragmatic, and focused on medical and technical procedures. Some women were glad the personnel never asked about emotional or moral issues:

And the healthcare is very into that, which was something I noticed, they're into not feeling guilt and shame. They don't try to just 'yes, but how does it really feel?' you know, but they are very pragmatic that way. (IP13, medical home abortion at age 23)

Others described the confrontation with the clinical environment as an 'odd' or 'weird' experience. For these women, the rational and technical routine was in stark contrast to the emotional experiences and choices they faced at the time: 


\section{Women's existential experiences... \\ Journal of Psychosomatic Obstetrics and Gynecology}

I got there in the morning and then I had to take that pill and then I was to go and sit down in a room where another girl was sitting, who was also going to do it. It felt really weird. It was like a cold room with two chairs and a table, and we were supposed to sit there with our pain. It was really strange. (IP18, medical abortion at age 22)

Although there may be nothing strange in this situation from a rational perspective, an individual dealing with an abortion might be confronted with questions about guilt, identity and meaning, which make the experience easier to understand. A number of women were dissatisfied with the lack of emotional response from the personnel before, during and/or after the medical procedure. They experienced the abortion care as distanced and felt the personnel avoided broaching any existential aspects of the situation. This was experienced in situations where the personnel avoided words that might upset the woman:

The doctor tried not to say 'foetus', she tried to avoid that word so I wouldn't think that way. /---/ Because the intention is that you shouldn't feel so much, that it should be as clinical as possible, right? (IP16, medical abortion at age 35)

It was also experienced in the personnel's focus on the medical and hygienic aspects:

They only spoke about that 'it is important that you don't take a bath, you cannot have sex, you...', well, how you were supposed to act. This part about it being difficult, that wasn't touched upon at all. (IP10, surgical abortion at age 18)

That no one mentioned the emotions involved felt particularly odd for women who were distressed during the medical procedures, due to their mixed feelings over the decision:

They didn't speak to me, I didn't get to see the doctor afterwards, even though I had been so upset, and even though it was kind of dramatic, and then I asked to see the journal because I wanted to see what they had written like as a discharge comment. Well, 'discharged to the home in good condition'. There was no one who had met me afterwards at all because I went home without telling them, and they didn't even try to reach me. Isn't that a bit weird? (IP7, surgical abortion at age 22)

Most women were informed about the possibility to talk with a counsellor if needed. This appeared important both for those who took the opportunity and for those who did not. However, while some women declined counselling although they felt a need for support, others did not find the counselling particularly supportive. Another complicating factor for emotional support was that several women explained existential thoughts about the abortion 


\section{Women's existential experiences... \\ Journal of Psychosomatic Obstetrics and Gynecology}

did not appear until sometime after they had been discharged from the clinic. Back at home,

they realised they would have needed some help to end the process:

This is something that I've never really finished, neither the first nor the second time, since there hasn't been time in some way you know... /---/ You know I don't regret that I did it, so it's not like that, but just to have closure, 'why did I do this,' and that you can reconcile, you know: 'It turned out the way it did, and it wasn't my fault. It wasn't my fault.' (IP3, medical reabortion at age 24)

The women were more or less involved in the abortion process

The women were involved in the abortion care to different extents and displayed different degrees of interest in taking an active part.

The personnel were in charge of the abortion process. Some women appreciated giving the responsibility for their unwanted pregnancy to the personnel, as they felt protected within the frames of the clinical routines. One way to achieve this was to choose surgical abortion, as it gave the women a possibility to avoid existentially difficult aspects:

In some way, it became so impersonal. You could escape the thoughts of what you really were doing, since you were anesthetised, but if you had been sitting in a clinic and waited to bleed it out, you know, you would have seen it, you would have known what was happening to the body. (IP4, surgical abortion at age 30)

However, in some cases, handing over responsibility turned into an experience of losing integrity and control. Women who were hesitant over the decision described how the personnel continued with the medical procedures despite them being emotionally upset, for example, putting them to sleep while they were crying on the operating table:

And then I started crying a lot, and the way I experienced it, they didn't stop right away, but anesthetised me quickly. And then I woke up and was really upset and I'm sure I screamed in the recovery ward and started to tear away the nose catheter with oxygen. (IP9, surgical reabortion at age 24)

The woman was in charge of the abortion process. Some women wanted to be more involved in the process, and were eager to understand and work through what was happening. For example, one woman described how she held the aborted foetus during her medical abortion and how this became a way to realise and reconcile what she was actually going through, which she appreciated: 
I was totally calm and could just sit there with the foetus in my hand and could look at it and that felt OK. 'You wouldn't have gotten a good life if you would have been born now', and then I flushed it down the toilet. /---/ It was difficult to deal with all the blood and all of that, but at the same time I'm happy that I got to experience the full process, to really understand what I was going through. (IP5, medical abortion at age 22)

However, some women found it difficult being involved in the abortion process, and could not decide how to take part. For example, during the ultrasound examination, the routine differed, some were shown the ultrasound picture, whether they wanted to see it or not, others felt they could not ask to see the picture. 


\section{Discussion}

Although the women had similar experiences of the abortion care offered, the needs they expressed differed. The women described the care at the abortion clinic as focused on physical matters, not on emotional or existential issues. For some women, the focus on physical matters was sufficient, and the neutral attitude of the personnel was appreciated. These women did not express any need for existential support from the personnel because they did not find the abortion particularly difficult to go through, or had found other ways to deal with these issues. In contrast, other women considered the clinical environment as impersonal and were disappointed by the absence of emotional or existential sensitivity among the personnel. These women expressed a need for greater focus on emotional and existential matters, which supported previous findings ${ }^{18}$.

The majority of women were satisfied with their abortion decision. However, complex existential issues of life, death, and morality were an important part of their experiences. This supported earlier studies: in one qualitative study ${ }^{14}$ ethical reasoning of existential matters were central in young Swedish women's abortion narratives, as also is shown in Carol Gilligan's classical study on women's moral and emotional development ${ }^{22}$, whereas, other studies ${ }^{11-13}$ highlight the complexity of abortion experiences. Existential issues appear an important, but often overlooked aspect in abortion research.

For some women, the medical procedures triggered existential experiences. For example, the ultrasound examination or the taking of the first pill made them acutely aware of both the situation and what they were experiencing: some women appreciated these moments, but others did not. The personnel had different routines during these situations: some women were upset they had to see the ultrasound picture unwillingly, and others were disappointed no one had offered them this opportunity. Women can make individual decisions about how to handle existentially dense aspects of abortion care, such as viewing the products of 
conception and the ultrasound picture ${ }^{23,24}$, and most women choosing to view the products of conception or the ultrasound picture find it a positive experience.

The general guidelines for nurses and midwives, established in 2005 by the Swedish National Board of Health and Welfare, states care should be characterised by a holistic and ethical worldview, where basic and specific health care needs should be met, including existential needs ${ }^{25}$. However, this study indicated existential needs might be neglected within Swedish abortion care. An unexpected pregnancy could challenge a woman's plans for her future, her worldview and identity. Unresolved, issues such as these, can trouble women for a long time; therefore, some form of obligatory debriefing could be complementary to the care offered. However, from a psychosomatic approach, the most important task for abortion personnel would be to relate to the patients more as people, in order to promote women's individual process for articulating the event ${ }^{26}$.

This in turn places more demand on the personnel, who must be prepared to tailor the care giving to the needs of the individual patient. In some cases, certain questions could arise that might provoke and disturb some patients, but are vital for others.

The initiation of existential issues in an environment dominated by high medical and technological standards is difficult, thus, it should be considered a part of an encompassing cultural process and as the responsibility of both the health care sector and institutions for social welfare and education ${ }^{27}$.

Suggestions for clinical practice:

1. There is a need to develop greater sensitivity and flexibility in relation to abortion care to meet women's different needs of involvement and support.

2. In order to do this, better resources and new lines of education are needed to ensure abortion personnel are equipped to deal with the existential aspects of abortion care. 


\section{Limitations}

As they were recruited at a student health clinic, the women in the present study were homogeneous in terms of ethnicity, social class, and education; thus, the material was not broad. However, the interviews varied and included rich stories about different abortion experiences. The retrospective outline of the study should be considered. The material consisted of twenty-four women's memories of abortions that had taken place between one month and over ten years before the interview; thus, there were differing times since the experience of abortion care, and the stories had probably been influenced by other life events. However, that the women considered it relevant to relate their abortion care experiences, even years after the abortions, highlighted the importance the event had for women beyond the immediate period of decision, medical procedure, and recovery. Many of the interviews revealed the woman's ability to understand and formulate her existential experiences related to abortion could develop over time.

\section{Conclusion}

Women's needs for existential support in relation to abortion vary. Some women abstain from any form of existential support; whereas, others express a need for support, and to reflect upon the existential aspects of the situation and/or to emotionally reconcile their decision. Swedish abortion care is described as rational and neutral, with physical issues dominating over emotional or existential and women can be disappointed with the personnel's lacking ability to respond to their thoughts and feelings related to the abortion.

This study highlights abortion care can be a demanding task, due to the diversity of emotional and existential experiences among abortion patients, and indicates a need for further knowledge, education and resources for delivering abortion care so each woman is treated according to her own individual physical, psychological, and existential needs. 


\section{Declaration of interest statement}

The study is a part of a centre of excellence program at Uppsala University University,

Sweden: Impact of Religion: Challenges to Society, Law and Democracy. The project was supported by the Swedish Council for Working Life and Social Research (FAS). 


\section{References}

1. Lipp A. A review of termination of pregnancy: prevalent health care professional attitudes and ways of influencing them. J Clin Nurs. 2008;17(13):1683-1688.

2. Mokgethi NE, Ehlers VJ, van der Merwe MM. Professional nurses' attitudes towards providing termination of pregnancy services in a tertiary hospital in the north west province of South Africa. Curationis. 2006;29(1):32-39.

3. Hammarstedt M, Jacobsson L, Wulff M, Lalos A. Views of midwives and gynecologists on legal abortion - a population-based study. Acta Obstetricia et Gynecologica Scandinavica. 2005;84(1):58-64.

4. Hammarstedt M, Lalos A, Wulff M. A population-based study of Swedish gynecologists' experiences of working in abortion care. Acta Obstetricia et Gynecologica Scandinavica. 2006;85(2):229-235.

5. Larsson M, Aneblom G, Odlind V, Tydén T. Reasons for pregnancy termination, contraceptive habits and contraceptive failure among Swedish women requesting an early pregnancy termination. Acta Obstet Gynecol Scand. 2002;81(1):64-71.

6. Major B, Appelbaum M, Beckman L, et al. Abortion and Mental Health: Evaluating the Evidence. American Psychologist. 2009;64(9):863-890.

7. Lipp A. Termination of pregnancy: a review of psychological effects on women. Nursing Times. 2009;105(1):26-29.

8. Charles VE, Polis CB, Sridhara SK, Blum RW. Abortion and long-term mental health outcomes: a systematic review of the evidence. Contraception. 2008;78(6):436-450.

9. Robinson GE, Stotland NL, Russo NF, Lang JA, Occhiogrosso M. Is there an 'abortion trauma syndrome'? Critiquing the evidence. Harv Rev Psychiatry. 2009;17(4):268-290.

10. Kero A, Högberg U, Lalos A. Wellbeing and mental growth - Long-term effects of legal abortion. Soc Sci Med. 2004;58(12):2559-2569.

11. Ekstrand M, Tydén T, Darj E, Larsson M. An Illusion of Power: Qualitative Perspectives On Abortion Decision-Making Among Teenage Women In Sweden. Perspectives on Sexual and Reproductive Health. 2009;41(3):173-180.

12. Kero A, Högberg U, Jacobsson L, Lalos A. Legal abortion: a painful necessity. Soc Sci Med. 2001;53(11):1481-1490.

13. Kero A, Lalos A. Ambivalence - a logical response to legal abortion: a prospective study among women and men. J Psychosom Obstet Gynaecol. 2000;21(2):81-91.

14. Halldén B, Christensson K, Olsson P. Early abortion as narrated by young Swedish women. Scand J Caring Sci. 2009;23(2):243-250.

15. Everly GS, Flannery RB, Eyler VA. Critical Incident Stress Management (CISM): a 
statistical review of the literature. Psychiatr Q. 2002;73(3):171-182.

16. Dietz D. Debriefing to help perinatal nurses cope with a maternal loss. MCN Am J Matern Child Nurs. 2009;34(4):243-248.

17. Mariutti MG, Almeida AMD, Panobianco MS. Nursing care according to women in abortion situations. Rev. Latino-Am. Enfermagem. 2007;15(1). Available at:

http://www.scielo.br/scielo.php?pid=S0104-

$11692007000100004 \&$ script=sci_arttext\&tlng=en [Accessed September 7, 2010].

18. Aléx L, Hammarström A. Women's experiences in connection with induced abortion - a feminist perspective. Scandinavian Journal of Caring Sciences. 2004;18(2):160-168.

19. Patton MQ. Qualitative research and evaluation methods. SAGE; 2002.

20. Graneheim UH, Lundman B. Qualitative content analysis in nursing research: concepts, procedures and measures to achieve trustworthiness. Nurse Education Today.

2004;24(2):105-112.

21. Kvale S. Interviews: an introduction to qualitative research interviewing. SAGE; 1996.

22. Gilligan C. In a different voice: psychological theory and women's development. Harvard University Press; 1993.

23. Wiebe ER, Adams LC. Women's experience of viewing the products of conception after an abortion. Contraception. 2009;80(6):575-577.

24. Wiebe ER, Adams LC. Women's perceptions about seeing the ultrasound picture before an abortion. The European Journal of Contraception \& Reproductive Health Care. 2009;14(2):97-102.

25. Kompetensbeskrivning for legitimerad sjukskoterska. 2005. Available at: http://www.socialstyrelsen.se/publikationer2005/2005-105-1 [Accessed September 7, 2010].

26. Bullington J, Nordemar R, Nordemar K, Sjöström-Flanagan C. Meaning out of chaos: a way to understand chronic pain. Scandinavian Journal of Caring Sciences. 2003;17(4):325331.

27. DeMarinis V. The Impact of Postmodernization on Existential Health in Sweden: Psychology of Religion's Function in Existential Public Health Analysis. Archive for the Psychology of Religion / Archiv für Religionspychologie. 2008;30:57-74. 


\section{Table I: Participant socio-demographics}

Number of women $(n=24)$

\begin{tabular}{lr}
\hline 1. Age at interview & 16 \\
$20-29$ years & 4 \\
$30-39$ years & 1 \\
$40-49$ years & 3 \\
$50-59$ years & 12 \\
\hline 2. Occupation at time of interview & 10 \\
Student & 1 \\
Employed & 1 \\
Sick leave/unemployed & 5 \\
No answer & 10 \\
\hline 3. Time since (last) abortion & 5 \\
<1 year ago & 4 \\
1-4 years ago & \\
5-9 years ago & 5 \\
9 years ago & 11 \\
\hline 4. Age at (last) abortion & 8 \\
15-19 years & \\
$20-24$ years & 14 \\
5-30 years & 11 \\
\hline Surgical abortion & 1 \\
Medical abortion & 5 \\
Two-step abortion & \\
Of which reabortions & \\
\hline 6. Gestation week at (last) abortion & \\
Before gestation week 12 & \\
After gestation week 12 & \\
& \\
\hline
\end{tabular}




\section{Table II: Categories and subcategories}

\begin{tabular}{|c|c|c|c|}
\hline Categories & $\begin{array}{l}\text { Medical procedures } \\
\text { evoked existential } \\
\text { experiences }\end{array}$ & $\begin{array}{l}\text { Personnel avoided the } \\
\text { existential aspects of the } \\
\text { situation }\end{array}$ & $\begin{array}{l}\text { The woman was more } \\
\text { or less involved in the } \\
\text { abortion process }\end{array}$ \\
\hline \multirow[t]{2}{*}{ Subcategories } & $\begin{array}{l}\text { The ultrasound made } \\
\text { the pregnancy real }\end{array}$ & $\begin{array}{l}\text { The personnel never } \\
\text { questioned the decision }\end{array}$ & $\begin{array}{l}\text { The personnel were in } \\
\text { charge of the abortion } \\
\text { process }\end{array}$ \\
\hline & $\begin{array}{l}\text { Taking the pill made the } \\
\text { choice irrevocable }\end{array}$ & $\begin{array}{l}\text { The personnel focused } \\
\text { on physical rather than } \\
\text { emotional issues }\end{array}$ & $\begin{array}{l}\text { The woman was in } \\
\text { charge of the abortion } \\
\text { process }\end{array}$ \\
\hline
\end{tabular}




\section{Current knowledge on this subject}

- A vast number of studies have shown that psychological distress after abortion is rare, in Sweden as well as in other countries.

- A number of studies have shown that the experience of abortion often includes strong emotions, sometimes related to existential questions.

- A few qualitative studies have shown that women experience abortion care as predominantly based on physical aspects, not considering the women's individual and emotional needs. 


\section{What this study adds}

- Women's experiences of abortion care are similar: The women in the study described Swedish abortion care as rational and neutral, with physical issues dominating over emotional or existential.

- Women's needs of existential support in relation to abortion are varied: While some women in the study were satisfied with a strictly medical care others expressed a need of existential and/or emotional support.

- The study indicates a need for further knowledge, education and resources to deliver abortion care where each woman is treated according not only to her physical and psychological, but also her existential needs. 